\title{
SISTEM PENDUKUNG KEPUTUSAN SELEKSI DOKUMEN PENAWARAN JASA KONSULTAN MENGGUNAKAN TOPSIS
}

\author{
Randy Purbo Haksomo ${ }^{1}$, Rudy Ariyanto ${ }^{2}$ \\ Program Studi Teknik Informatika, Jurusan Teknologi Informasi, Politeknik Negeri Malang \\ randypurbohaksomo@gmail.com, ${ }^{2}$ ariyantorudy@gmail.com
}

\begin{abstract}
Abstrak
Evaluasi dokumen penawaran teknis dilakukan dengan cara memberikan nilai angka tertentu pada setiap kriteria yang dinilai dan di berikan bobot, kemudian membandingkan jumlah perolehan nilai dari peserta dan Hasil evaluasi teknis harus melewati ambang batas nilai teknis (passing grade) juga perhitungan yang dilakukan masih secara manual. Agar dapat mengatasi masalah diatas maka Rumah Sakit Jiwa Dr. Radjiman Wediodiningrat Lawang ini memerlukan suatu sistem pendukung keputusan (Decision Support System) atau SPK (Sistem Pendukung Keputusan). Sedangkan penulis memilih salah satu metode dalam pembuatan SPK yaitu Technique Order Preference by Similarity To Ideal Solution (TOPSIS) yang memiliki Kelebihan antara lain TOPSIS digunakan untuk menyelesaikan suatu masalah dengan beragam kriteria dengan menerapkan bobot nilai pada setiap kriterianya. Karena kemampuannya untuk menghitung banyak kriteria sehingga sesuai untuk menyelesaikan masalah yang dihadapi. Berdasarkan penelitian yang dilaksanakan oleh penulis pada pengembangan sistem pendukung keputusan, dapat ditarik kesimpulan bahwa sistem ini telah di implementasikan dengan baik ,maupun secara validasi sistem dan akurasi yang mencapai $100 \%$.
\end{abstract}

Kata kunci : sistem pendukung keputusan, evaluasi, TOPSIS.

\section{Pendahuluan}

Menurut dokumen pengadaan pengadaan secara elektronik tentang pengadaan jasa konsultasi badan usaha menyatakan bahwa evaluasi dokumen penawaran teknis dilakukan dengan cara memberikan nilai angka tertentu pada setiap kriteria yang dinilai dan bobot yang telah ditetapkan dalam dokumen pemilihan, kemudian membandingkan jumlah perolehan nilai dari peserta, dengan ketentuan kriteria pokok yang dinilai adalah pengalaman perusahaan ,Pendekatan dan metodologi dan kualifikasi tenaga ahli. Sedangkan setiap kriteria pokok juga memiliki subkriteria yang harus dinilai dan juga memiliki bobot yang berbeda. Bobot masing-masing unsur ditetapkan oleh Pokja ULP berdasarkan jenis pekerjaan yang akan dilaksanakan. Hasil evaluasi teknis harus melewati ambang batas nilai teknis (passing grade) seperti yang tercantum dalam Lembar Data Pemilihan.

Karakteristik evaluasi pada pengadaan jasa konsultansi adalah pekerjaan bersifat kompleks sehingga diperlukan evaluasi teknis yang lebih mendalam dan seleksi ini memiliki kriteria dan subkriteria yang banyak serta memiliki bobot yang berbeda, dan juga perhitungan yang dilakukan masih secara manual dan keputusan seringkali dipengaruhi faktor emosi dari pengambil keputusan sehingga kurang akurat dan kurang efisien dari segi waktu dalam proses seleksi. Agar dapat mengatasi masalah diatas maka Rumah Sakit Jiwa Dr. Radjiman Wediodiningrat Lawang ini memerlukan suatu sistem pendukung keputusan (Decision Support System) atau SPK (Sistem Pendukung Keputusan). Sedangkan penulis memilih salah satu metode dalam pembuatan SPK yaitu Technique Order Preference by Similarity To Ideal Solution (TOPSIS) yang memiliki Kelebihan antara lain TOPSIS digunakan untuk menyelesaikan suatu masalah dengan beragam kriteria dengan menerapkan bobot nilai pada setiap kriterianya. Karena kemampuannya untuk menghitung banyak kriteria sehingga sesuai untuk menyelesaikan masalah yang dihadapi. Diharapkan Metode Topsis dapat memberikan alternatif pada pembuat keputusan dalam seleksi dokumen penawaran pembangunan gedung.

\section{Tinjauan Pustaka}

\subsection{Sistem Pendukung Keputusan}

Sistem pendukung keputusan merupakan suatu sistem interaktif yang mendukung keputusan dalam proses pengambilan keputusan melalui alternatifalternatif yang diperoleh dari hasil pengolahan data, informasi dan rancangan model. Menurut Keen dan Scoot Morton : "Sistem Pendukung Keputusan merupakan penggabungan sumber-sumber kecerdasan individu dengan kemampuan komponen untuk memperbaiki kualitas keputusan. Sistem Pendukung Keputusan juga merupakan sistem informasi berbasis komputer untuk manajemen pengambilan keputusan yang menangani masalahmasalah semi-struktur”. 


\subsection{Dokumen Penawaran}

Dokumen penawaran merupakan salah satu syarat untuk mengikuti Pengadaan barang atau jasa pemerintah, khusunya pada pengadaan jasa konsultan menurut Standar Dokumen Pemilihan Secara Elektronik yang dibuat oleh Lembaga Kebijakan Pengadaan Barang/Jasa Pemerintah.

\subsection{TOPSIS}

TOPSIS adalah salah satu metode pengambilan keputusan multikriteria yang pertama kali diperkenalkan oleh Yoon dan Hwang pada tahun 1981. TOPSIS menggunakan prinsip bahwa alternatif yang terpilih harus mempunyai jarak terdekat dari solusi ideal positif dan terjauh dari solusi ideal negatif

Adapun langkah-langkah algoritma dari TOPSIS ini adalah sebagai berikut (Aris Munandar Tito,2014) :

\section{a. Rangking Tiap Alternatif}

TOPSIS membutuhkan ranking kinerja setiap alternatif $\mathrm{Ai}$ pada setiap kriteria $\mathrm{Cj}$ yang ternormalisasi yaitu :

$$
r_{i j}=\frac{x_{i j}}{\sqrt{\sum_{i-1}^{m} x_{i j}^{2}}}
$$

dengan $i=1,2, \ldots . m$; dan $j=1,2, \ldots \ldots . n$.

b. Matriks keputusan ternormalisasi terbobot

$y_{i j}=w_{i} r_{i j}$

Dengan $\mathrm{i}=1,2, \ldots, \mathrm{m} ;$ dan $\mathrm{j}=1,2, \ldots, \mathrm{n}$

c. Solusi Ideal Positif Dan Negatif

Solusi ideal positif A+ dan solusi ideal negatif Adapat ditentukan berdasarkan ranking bobot ternormalisasi (yij) sebagai berikut :

$$
\begin{aligned}
& A^{+}=\left(y_{1}^{+}, y_{2}^{+}, \ldots, y_{n}^{+}\right) . \\
& A^{-}=\left(y_{1}^{-}, y_{2}^{-}, \ldots, y_{n}^{-}\right) .
\end{aligned}
$$

dengan

$$
y_{j}^{+}=
$$

$\max _{i j} j_{i j} ; j i k a j$ adalah atribut keuntungan

$\left\{\min _{i} j_{i j} ; j i k a j\right.$ adalah atribut biaya

$$
y_{j}^{-}=
$$

$\left\{\min _{i} j_{i j} ; j i k a j\right.$ adalah atribut keuntungan

$\left\{\max _{i} j_{i j} ; j i k a j\right.$ adalah atribut biaya

$$
\mathrm{j}=1,2, \ldots, \mathrm{n}
$$

d. Jarak Dengan Solusi Ideal

Jarak antara alternatif $A_{i}$ dengan solusi ideal positif dirumuskan sebagai:

$$
\begin{aligned}
& D_{i}^{+}=\sqrt{\sum_{j=1}^{n}\left(y_{i}^{+}-y_{i j}\right)^{2}} \ldots \\
& \text { Dengan } \mathrm{i}=1,2, \ldots, \mathrm{m}
\end{aligned}
$$

Jarak antara alternatif $A_{i}$ dengan solusi ideal negatif dirumuskan sebagai:

$\frac{D_{i}^{-}=}{\sqrt{\sum_{j=1}^{n}\left(y_{i j}-y_{i}^{-}\right)^{2}} \ldots}$ dengan $\mathrm{i}=1,2, \ldots, \mathrm{m}$

e. Nilai Preferensi Untuk Setiap Alternatif

Nilai preferensi untuk setiap alternatif (Vi) diberikan sebagai :

$$
V_{i}=\frac{D_{i}^{-}}{D_{i}^{-}+D_{i}^{+}}
$$

Dengan $\mathrm{i}=1,2, \ldots, \mathrm{m}$

Nilai Vi yang lebih besar menunjukkan bahwa alternatif Ai lebih dipilih.

\section{Analisa dan Perancangan}

\subsection{Gambaran Sistem}

Gambaran umum dari tempat penelitian adalah sebagai berikut. pertama panitia akan memasukan nama tender dan ambang batas yang digunakan kemudian memasukan instansi untuk menjadi peserta, kemudian masukan pembobotan lalu melakukan penilaian terhadap peserta di setiap kriteria, tahap selanjutnya melakukan penilaian terhadap peserta dengan nilai dan bobot sebagai acuan, lali akan didapatkan hasil akhir atau nilai akhir dari peserta lalu nilai akhir peserta tersebut akan dibadingkan dengan ambang batas apabila nilai akhir peserta kurang dari ambang batas maka dinyatakan gagal sedangkan jika nilai akhir peserta diatas ambang batas maka dinyatakan lulus. Setelah selesai maka akan dibuat laporan hasil dari seleksi tadi

\subsection{Data Kriteria dan bobot}

Terdapat 25 kriteriayang digunakan dalam sistem yang akan terjadi pada sistem pendukung keputusan seleksi dokumen penawaran jasa konsultan antara lain sebagai berikut :

\begin{tabular}{|l|l|r|}
\hline No & Nama Kriteria & Bobot \\
\hline 1 & $\begin{array}{l}\text { Pengalaman melaksanakan } \\
\text { kegiatan sejenis }\end{array}$ & $8 \%$ \\
\hline 2 & $\begin{array}{l}\text { Pengalaman melaksanakan di } \\
\text { lokasi kegiatan }\end{array}$ & $4 \%$ \\
\hline 3 & Pengalaman menjadi lead firm & $1,33 \%$ \\
\hline 4 & $\begin{array}{l}\text { Pengalaman mengelola kontrak } \\
\text { tertinggi }\end{array}$ & $1,33 \%$ \\
\hline 5 & Ketersediaan fasilitas utama & $1,34 \%$ \\
\hline 6 & $\begin{array}{l}\text { Kapasitas perusahaan dengan } \\
\text { memperhatikan jumlah tenaga } \\
\text { ahli tetap }\end{array}$ & $4 \%$ \\
\hline 7 & $\begin{array}{l}\text { Pemahaman atas jasa layanan } \\
\text { yang tercamtum dalam KAK }\end{array}$ & $5 \%$ \\
\hline 8 & $\begin{array}{l}\text { Ketepatan analisa yang } \\
\text { disampaikan dan langkah yang } \\
\text { diusulkan. }\end{array}$ & $0,75 \%$ \\
\hline 9 & $\begin{array}{l}\text { Kosistensi antara metodologi } \\
\text { dengan rencana kerja }\end{array}$ & $0,75 \%$ \\
\hline 10 & Apresiasi terhadap inovasi & $0,75 \%$ \\
\hline
\end{tabular}




\begin{tabular}{|l|l|r|}
\hline 11 & $\begin{array}{l}\text { Dukumgam data yang tersedia } \\
\text { terhadap KAK }\end{array}$ & $0,75 \%$ \\
\hline 12 & Uraian tugas & $0,50 \%$ \\
\hline 13 & Jangka waktu pelaksanaan & $0,50 \%$ \\
\hline 14 & $\begin{array}{l}\text { Program kerja,jadwal perkerjaan } \\
\text { dan jadwal penugasan }\end{array}$ & $0,50 \%$ \\
\hline 15 & Organisasi & $0,25 \%$ \\
\hline 16 & Kebutuhan fasilitas penunjang & $0,25 \%$ \\
\hline 17 & $\begin{array}{l}\text { Penyajian analisis dan gambar- } \\
\text { gambar kerja }\end{array}$ & $2 \%$ \\
\hline 18 & $\begin{array}{l}\text { Penyajian spesifikasi teknis dan } \\
\text { perhitungan teknis }\end{array}$ & $1,50 \%$ \\
\hline 19 & Penyajian laporan & $1,50 \%$ \\
\hline 20 & Gagasan baru & $5 \%$ \\
\hline 21 & Tingkat pendidikan & $10 \%$ \\
\hline 22 & Dukungan referensi & $15 \%$ \\
\hline 23 & Bulan kerja tenaga ahli & $15 \%$ \\
\hline 24 & Sertifikat keahlian & $10 \%$ \\
\hline 25 & Posisi tenaga ahli & $10 \%$ \\
\hline
\end{tabular}

\subsection{Cara Penilaian}

Cara penilaian terhadap kriteria yang dgunakan adalah sebagai berikut:

Tabel 2. Kriteria

\begin{tabular}{|c|c|c|}
\hline No & $\begin{array}{l}\text { Nama } \\
\text { Kriteria }\end{array}$ & Cara Penilaian \\
\hline 1 & $\begin{array}{l}\text { Pengalam } \\
\text { an } \\
\text { melaksan } \\
\text { akan } \\
\text { kegiatan } \\
\text { sejenis }\end{array}$ & $\begin{array}{l}\text { Nilai diambil dari Jumlah } \\
\text { paket pengalaman } \\
\text { perusahaan yang paling } \\
\text { banyak dijadikan pembanding } \\
\text { untuk mendapatkan nilai. } \\
\text { Dengan rumus= nilai } \\
\text { pengalaman /nilai } \\
\text { pengalaman tertinggi }\end{array}$ \\
\hline 2 & $\begin{array}{l}\text { Pengalam } \\
\text { an } \\
\text { melaksan } \\
\text { akan di } \\
\text { lokasi } \\
\text { kegiatan }\end{array}$ & $\begin{array}{l}\text { Dihitung jumlah paket } \\
\text { pengalaman perusahaan pada } \\
\text { pekerjaan yang sesuai pada } \\
\text { lokasi kegiatan } \\
\text { (Provinsi/Kabupaten/Kota). } \\
\text { Jumlah paket pengalaman } \\
\text { perusahaan yang paling } \\
\text { banyak di lokasi kegiatan } \\
\text { tersebut, dijadikan } \\
\text { pembanding untuk } \\
\text { mendapatkan nilai. Dengan } \\
\text { rumus= nilai pengalaman di } \\
\text { lokasi / nilai pengalaman } \\
\text { tertinggi di lokasi }\end{array}$ \\
\hline 3 & $\begin{array}{l}\text { Pengalam } \\
\text { an } \\
\text { menjadi } \\
\text { lead firm }\end{array}$ & $\begin{array}{l}\text { Dihitung jumlah pengalaman } \\
\text { menjadi lead firm. Jumlah } \\
\text { yang paling banyak, dijadikan } \\
\text { pembanding untuk } \\
\text { mendapatkan nilai. } \\
\text { Rumus = nilai pengalaman } \\
\text { sebagai lead firm / nilai }\end{array}$ \\
\hline
\end{tabular}

\begin{tabular}{|c|c|c|}
\hline & & $\begin{array}{l}\text { pengalaman lead firm } \\
\text { tertinggi }\end{array}$ \\
\hline 4 & $\begin{array}{l}\text { Pengalam } \\
\text { an } \\
\text { mengelola } \\
\text { kontrak } \\
\text { tertinggi }\end{array}$ & $\begin{array}{l}\text { Dihitung nilai kontrak } \\
\text { tertinggi dari pekerjaan yang } \\
\text { sejenis. Nilai kontrak yang } \\
\text { tertinggi, dijadikan } \\
\text { pembanding untuk } \\
\text { mendapatkan nilai.Rumus = } \\
\text { nilai pengalaman kontrak/nilai } \\
\text { pengalaman kontrak tertinggi. }\end{array}$ \\
\hline 5 & $\begin{array}{l}\text { Ketersedi } \\
\text { aan } \\
\text { fasilitas } \\
\text { utama }\end{array}$ & $\begin{array}{l}\text { Jika ada maka nilai } 1 \text { dan jika } \\
\text { tidak ada nilai } 0\end{array}$ \\
\hline 6 & $\begin{array}{l}\text { Kapasitas } \\
\text { perusahaa } \\
\mathrm{n} \text { dengan } \\
\text { memperh } \\
\text { atikan } \\
\text { jumlah } \\
\text { tenaga } \\
\text { ahli tetap }\end{array}$ & $\begin{array}{l}\text { Dihitung jumlah tenaga ahli } \\
\text { tetap terbanyakuntuk } \\
\text { kemudian dijadikan } \\
\text { pembanding untuk } \\
\text { mendapatkan nilai. Rumus = } \\
\text { jumlah tenaga ahli tetap / } \\
\text { jumlah ahli tetap terbanyak. }\end{array}$ \\
\hline 7 & $\begin{array}{l}\text { Pemaham } \\
\text { an atas } \\
\text { jasa } \\
\text { layanan } \\
\text { yang } \\
\text { tercamtu } \\
\text { m dalam } \\
\text { KAK }\end{array}$ & $\begin{array}{l}\text { Tanggapan sangat baik }=1 \\
\text { Tanggpan baik }=0,8 \\
\text { Tanggapan cukup baik }=0,6 \\
\text { Tanggapan kurang }=0,4 \\
\text { Tanggapan sangat kurang }= \\
0,2 \\
\text { Tidak memberikan tanggapan } \\
=0\end{array}$ \\
\hline 8 & $\begin{array}{l}\text { Ketepatan } \\
\text { analisa } \\
\text { yang } \\
\text { disampaik } \\
\text { an dan } \\
\text { langkah } \\
\text { yang } \\
\text { diusulkan. }\end{array}$ & $\begin{array}{l}\text { sangat baik }=1 \\
\text { baik }=0,8 \\
\text { cukup baik }=0,6 \\
\text { kurang }=0,4 \\
\text { sangat kurang }=0,2 \\
\text { tidak menyampaikan =0 }\end{array}$ \\
\hline 9 & $\begin{array}{l}\text { Kosistensi } \\
\text { antara } \\
\text { metodolo } \\
\text { gi dengan } \\
\text { rencana } \\
\text { kerja }\end{array}$ & $\begin{array}{l}\text { sangat baik }=1 \\
\text { baik }=0,8 \\
\text { cukup baik }=0,6 \\
\text { kurang }=0,4 \\
\text { sangat kurang =0,2 } \\
\text { tidak menyampaikan }=0\end{array}$ \\
\hline 10 & $\begin{array}{l}\text { Apresiasi } \\
\text { terhadap } \\
\text { inovasi }\end{array}$ & $\begin{array}{l}\text { sangat baik }=1 \\
\text { baik }=0,8 \\
\text { cukup baik }=0,6 \\
\text { kurang }=0,4 \\
\text { sangat kurang }=0,2 \\
\text { tidak menyampaikan }=0\end{array}$ \\
\hline 11 & $\begin{array}{l}\text { Dukumga } \\
\text { m data } \\
\text { yang } \\
\text { tersedia } \\
\text { terhadap } \\
\text { KAK }\end{array}$ & $\begin{array}{l}\text { sangat baik }=1 \\
\text { baik }=0,8 \\
\text { cukup baik }=0,6 \\
\text { kurang }=0,4 \\
\text { sangat kurang }=0,2 \\
\text { tidak menyampaikan }=0\end{array}$ \\
\hline
\end{tabular}




\begin{tabular}{|c|c|c|}
\hline 12 & $\begin{array}{l}\text { Uraian } \\
\text { tugas }\end{array}$ & $\begin{array}{l}\text { sangat baik }=1 \\
\text { baik }=0,8 \\
\text { cukup baik }=0,6 \\
\text { kurang }=0,4 \\
\text { sangat kurang }=0,2 \\
\text { tidak menyampaikan }=0\end{array}$ \\
\hline 13 & $\begin{array}{l}\text { Jangka } \\
\text { waktu } \\
\text { pelaksana } \\
\text { an }\end{array}$ & $\begin{array}{l}\text { sangat baik }=1 \\
\text { baik }=0,8 \\
\text { cukup baik }=0,6 \\
\text { kurang }=0,4 \\
\text { sangat kurang }=0,2 \\
\text { tidak menyampaikan }=0\end{array}$ \\
\hline 14 & $\begin{array}{l}\text { Program } \\
\text { kerja,jadw } \\
\text { al } \\
\text { perkerjaa } \\
\text { n dan } \\
\text { jadwal } \\
\text { penugasa } \\
\text { n }\end{array}$ & $\begin{array}{l}\text { sangat baik }=1 \\
\text { baik }=0,8 \\
\text { cukup baik }=0,6 \\
\text { kurang }=0,4 \\
\text { sangat kurang }=0,2 \\
\text { tidak menyampaikan }=0\end{array}$ \\
\hline 15 & Organisasi & $\begin{array}{l}\text { sangat baik }=1 \\
\text { baik }=0,8 \\
\text { cukup baik }=0,6 \\
\text { kurang }=0,4 \\
\text { sangat kurang }=0,2 \\
\text { tidak menyampaikan }=0\end{array}$ \\
\hline 16 & $\begin{array}{l}\text { Kebutuha } \\
\mathrm{n} \text { fasilitas } \\
\text { penunjan } \\
\mathrm{g}\end{array}$ & $\begin{array}{l}\text { sangat baik }=1 \\
\text { baik }=0,8 \\
\text { cukup baik }=0,6 \\
\text { kurang }=0,4 \\
\text { sangat kurang }=0,2 \\
\text { tidak menyampaikan }=0\end{array}$ \\
\hline 17 & $\begin{array}{l}\text { Penyajian } \\
\text { analisis } \\
\text { dan } \\
\text { gambar- } \\
\text { gambar } \\
\text { kerja } \\
\end{array}$ & $\begin{array}{l}\text { sangat baik }=1 \\
\text { baik }=0,8 \\
\text { cukup baik }=0,6 \\
\text { kurang }=0,4 \\
\text { sangat kurang }=0,2 \\
\text { tidak menyampaikan }=0\end{array}$ \\
\hline 18 & $\begin{array}{l}\text { Penyajian } \\
\text { spesifikasi } \\
\text { teknis dan } \\
\text { perhitung } \\
\text { an teknis }\end{array}$ & $\begin{array}{l}\text { sangat baik }=1 \\
\text { baik }=0,8 \\
\text { cukup baik }=0,6 \\
\text { kurang }=0,4 \\
\text { sangat kurang }=0,2 \\
\text { tidak menyampaikan }=0\end{array}$ \\
\hline 19 & $\begin{array}{l}\text { Penyajian } \\
\text { laporan }\end{array}$ & $\begin{array}{l}\text { sangat baik }=1 \\
\text { baik }=0,8 \\
\text { cukup baik }=0,6 \\
\text { kurang }=0,4 \\
\text { sangat kurang }=0,2 \\
\text { tidak menyampaikan }=0\end{array}$ \\
\hline 20 & $\begin{array}{l}\text { Gagasan } \\
\text { baru }\end{array}$ & $\begin{array}{l}\text { sangat baik }=1 \\
\text { baik }=0,8 \\
\text { cukup baik }=0,6 \\
\text { kurang }=0,4 \\
\text { sangat kurang }=0,2 \\
\text { tidak menyampaikan }=0\end{array}$ \\
\hline
\end{tabular}

\begin{tabular}{|l|l|l|}
\hline 21 & $\begin{array}{l}\text { Tingkat } \\
\text { pendidika } \\
\mathrm{n}\end{array}$ & $\begin{array}{l}\text { Sesuai }=1 \\
\text { Tidak sesuai }=0\end{array}$ \\
\hline 22 & $\begin{array}{l}\text { Dukungan } \\
\text { referensi }\end{array}$ & $\begin{array}{l}\text { Melampirkan }=1 \\
\text { Tidak melampirkan }=0\end{array}$ \\
\hline 23 & $\begin{array}{l}\text { Bulan } \\
\text { kerja } \\
\text { tenaga } \\
\text { ahli }\end{array}$ & $\begin{array}{l}\text { Sesuai }=1 \\
\text { Menunjang/terkait }=0,5\end{array}$ \\
\hline 24 & $\begin{array}{l}\text { Sertifikat } \\
\text { keahlian }\end{array}$ & $\begin{array}{l}\text { Memiliki }=1 \\
\text { Tidak memiliki }=0\end{array}$ \\
\hline 25 & $\begin{array}{l}\text { Posisi } \\
\text { tenaga } \\
\text { ahli }\end{array}$ & $\begin{array}{l}\text { Sesuai }=1 \\
\text { Tidak Sesuai }=0\end{array}$ \\
\hline
\end{tabular}

\section{Uji Coba dan Pembahasan}

\subsection{Uji Coba}

\subsubsection{Uji Coba Perhitunga}

\section{A. Data Uji Coba}

Data uji coba menggunakan data sample alternatif dengan kriteria yang berjumlah 25 dan karena jumlah kriteria yang banyak maka yang ditampilkan hanya 2 kriteria awal dan 2 kriteria akhir. Dan berikut ini adalah data yang akan digunakan untuk sistem pendukung keputusan seleksi dokumen penawaran jasa konsultan.

\begin{tabular}{|c|c|c|c|c|}
\hline \multicolumn{5}{|c|}{ Tabel 3 Data } \\
\hline & K1 & K2 & K24 & K25 \\
\hline A1 & 0,556 & 1 & 0,5 & 1 \\
\hline A2 & 0,778 & 0,834 & 0,5 & 1 \\
\hline A3 & 1 & 0,667 & 1 & 1 \\
\hline
\end{tabular}

B. Menentukan matriks keputusan ternormalisasi (ranking antar alternatif)

Dengan menggunakan persamaan (1) maka matriks keputusan ternormalisasi

Tabel 4. Matriks Ternormalisasi

\begin{tabular}{|c|c|c|c|c|}
\hline & K1 & K2 & K24 & K25 \\
\hline A1 & 0,4016 & 0.6837 & 0,5773 & 0.5773 \\
\hline A2 & 0.5622 & 0.5698 & 0.5773 & 0.5773 \\
\hline A3 & 0.7228 & 0.6286 & 0.5773 & 0.5773 \\
\hline
\end{tabular}

C. Menentukan matriks keputusan ternormalisasi terbobot

Dengan menggunakan persamaan (2) maka matriks keputusan ternormalisasi terbobot ditunjukkan pada Tabel 5.

Tabel 5. Matriks Ternormalisasi Terbobot

\begin{tabular}{|c|c|c|c|c|}
\hline & K1 & K2 & K24 & K25 \\
\hline A1 & 0.0321 & 0,0273 & 0.0577 & 0.0577 \\
\hline A2 & 0.0449 & 0.0227 & 0.0577 & 0.0577 \\
\hline A3 & 0.0578 & 0.0182 & 0.0577 & 0.0577 \\
\hline
\end{tabular}


D. Menentukan nilai solusi ideal positif dan solusi ideal negatif

Dengan menggunakan persamaan (3) dan persamaan (4) maka didapatkan solusi ideal positif dan negatif ditunjukkan pada Tabel 6 .

Tabel 6. Nilai Solusi Ideal Positif dan Solusi Ideal Negatif

\begin{tabular}{|c|c|c|c|c|}
\hline & K1 & K2 & K24 & K25 \\
\hline$A^{+}$ & 0,0578 & 0.0273 & 0.0577 & 0.0577 \\
\hline$A^{-}$ & 0.0321 & 0.0182 & 0.0577 & 0.0577 \\
\hline
\end{tabular}

E. Menentukan jarak antar nilai alternatif dengan solusi ideal positif dan solusi ideal negatif

Dengan menggunakan persamaan (5) dan persamaan (6) maka jarak antar nilai alternatif dengan solusi ideal positif dan negatif pada Tabel 7.

Tabel 7. Jarak Antar Nilai Alternatif dengan Solusi Ideal Positif dan Negatif

\begin{tabular}{|c|c|c|}
\hline & $\boldsymbol{D}^{+}$ & $\boldsymbol{D}^{-}$ \\
\hline A1 & 0.1701 & 0.0822 \\
\hline A2 & 0.1821 & 0.0468 \\
\hline A3 & 0.0453 & 0.1809 \\
\hline
\end{tabular}

F. Menentukan nilai preferensi untuk setiap alternatif

Dengan menggunakan persamaan (7) didapatkan nilai preferensi untuk setiap alternatif ditunjukkan pada Tabel 8.

\section{Tabel 8 Nilai Preferensi}

\begin{tabular}{|c|c|}
\hline & $\boldsymbol{V}$ \\
\hline A1 & 0,3257 \\
\hline A2 & 0.2046 \\
\hline A3 & 0.7997 \\
\hline
\end{tabular}

\subsubsection{Uji Coba Hasil}

Uji coba hasil terhadap empat kriteria dengan membandingkan hasil perhitungan manual dan hasil perhitungan menggunakan SPK. Untuk 2 tender dibawah ini.

Tabel 9 Perbandingan Hasil Uji Coba

\begin{tabular}{|l|l|l|l|}
\hline $\begin{array}{l}\text { Nama } \\
\text { Tender }\end{array}$ & Peserta & $\begin{array}{l}\text { Hasil } \\
\text { Perhitun } \\
\text { gan } \\
\text { Manual }\end{array}$ & $\begin{array}{l}\text { Hasil } \\
\text { Sistem }\end{array}$ \\
\hline Olahraga & $\begin{array}{l}\text { CV } \\
\text { Restu } \\
\text { Graha } \\
\text { Cipta }\end{array}$ & 0,799774 & 0,799774 \\
\cline { 2 - 4 } & $\begin{array}{l}\text { PT } \\
\text { Titimat } \\
\text { ra } \\
\text { Tujuta } \\
\text { ma }\end{array}$ & 0,325759 & 0,325759 \\
\hline
\end{tabular}

\begin{tabular}{|l|l|l|l|}
\hline & $\begin{array}{l}\text { PT } \\
\text { Rekanci } \\
\text { pta } \\
\text { Konsuli } \\
\text { ndo }\end{array}$ & 0,204647 & 0,204647 \\
\hline Pelayanan & $\begin{array}{l}\text { PT } \\
\text { Ranmuj } \\
\text { a }\end{array}$ & 0,596086 & 0,596086 \\
\cline { 2 - 4 } & $\begin{array}{l}\text { PT } \\
\text { Arkoni } \\
\mathrm{n}\end{array}$ & 0,554983 & 0,554983 \\
\cline { 2 - 4 } & $\begin{array}{l}\text { PT } \\
\text { Kanta } \\
\text { Karya } \\
\text { Utama }\end{array}$ & 0,425748 & 0,425748 \\
\cline { 2 - 4 } & $\begin{array}{l}\text { PT } \\
\text { Sangku } \\
\text { riang }\end{array}$ & 0,40629 & 0,40629 \\
\hline
\end{tabular}

\subsubsection{Pengujian Efisiensi Waktu}

Uji coba efisiensi waktu akan dilakukan dengan cara membandingkan waktu yang dibutuhkan untuk menyelesaikan evaluasi dokumen teknis suatu tender dengan menggunakan metode TOPSIS antara menggunakan excel dan sistem yang dibangun ini dengan menggunakan data pada tabel 5.2 sampai dengan tabel 5.6. kemudian rumus untuk menghitung efisiensinya adalah dengan cara (100( Waktu yamg dibutuhkan sistem - Waktu yamg dibutuhkan excel )*100). Hasil dari pengujian efisiensi waktu adalah sebagai berikut :

\begin{tabular}{|c|c|c|c|c|}
\hline $\begin{array}{l}\text { Nama } \\
\text { Tender }\end{array}$ & $\begin{array}{l}\text { Jum } \\
\text { lah }\end{array}$ & $\begin{array}{l}\text { excel } \\
\text { (menit) }\end{array}$ & $\begin{array}{l}\text { sisem } \\
\text { (meni } \\
\text { t) }\end{array}$ & $\begin{array}{l}\text { Efisiensi } \\
(\%)\end{array}$ \\
\hline $\begin{array}{l}\text { Olahra } \\
\text { ga }\end{array}$ & 3 & 7 & 5 & $\begin{array}{r}28,571 \\
43\end{array}$ \\
\hline $\begin{array}{l}\text { Pelaya } \\
\text { nan }\end{array}$ & 4 & 10 & 7 & 30 \\
\hline $\begin{array}{l}\text { Labotar } \\
\text { ium }\end{array}$ & 5 & 14 & 9 & $\begin{array}{r}35,714 \\
29 \\
\end{array}$ \\
\hline Klinik & 6 & 16 & 12 & 25 \\
\hline $\begin{array}{l}\text { Perawa } \\
\text { tan }\end{array}$ & 2 & 5 & 3 & 40 \\
\hline \multicolumn{4}{|c|}{ Rata-Rata } & 31,8571 \\
\hline
\end{tabular}

\subsection{Pembahasan}

Setelah dilakukan uji coba perhitungan dan dilakukan perbandingan hasil maka hasil kinerja SPK tersebut mendapatkan nilai akurasi $100 \%$ pada gambar 2.Pada gambar 3 menunjukan efiseiensi waktu meningkat $31,85714 \%$. 


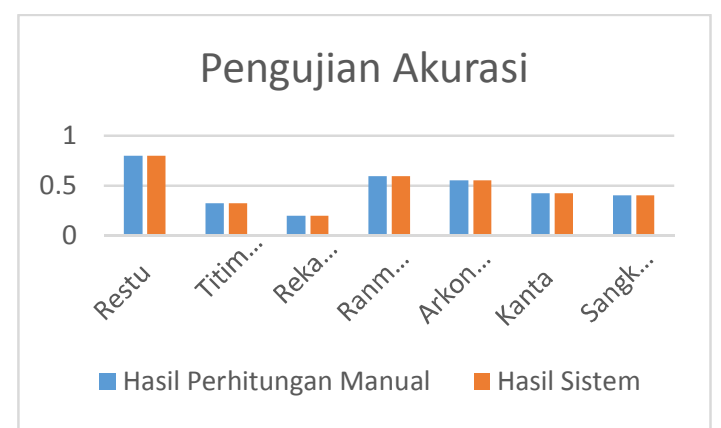

Gambar 1. Hasil Akurasi

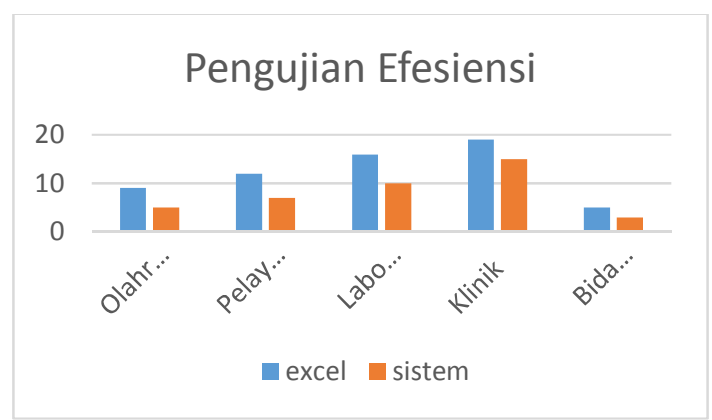

Gambar 2. Hasil Efisiensi Waktu

\section{Kesimpulan dan Saran}

\subsection{Kesimpulan}

Berdasarkan penelitian yang dilaksanakan oleh penulis pada pengembangan sistem pendukung keputusan seleksi dokumen penawaran jasa konsultan pembangunan gedung dengan metode topsis rumah sakit jiwa dr. Radjiman wediodiningrat lawang, dapat ditarik kesimpulan bahwa sistem telah berhasil menerapkan metode TOPSIS dan telah dibuat sesuai rancangan. Hasil uji coba sistem ini menunjukan bahwa sistem ini telah dibuat sesuai dengan fungsionalitas yang diharapkan. Kemudian hasil uji coba akurasi yang membandingkan perhitungan dengan menggunakan excel dengan menggunakan sistem menunjukan bahwa sistem ini telah implementasi sistem ini sudah sesuai. Pengujian efisiensi waktu yang membandingkan waktu yang dibutuhkan untuk menyelesaikan evaluasi dengan metode TOPSIS antara excel dan sistem menunjukan bahwa sistem ini menigkatkan efisiensi waktu sebesar $31,85714 \%$.

\subsection{Saran}

Saran untuk sistem ini adalah agar membuat semua evaluasi bukan hanya evaluasi tender gedung tetapi juga semua tender yang belum ada sistemnya karena jenis tender lain akan memiliki kriteria yang berbeda pula.

\section{Daftar Pustaka :}

Anonimous, 2010. Peraturan Presiden Republik Indonesia Nomor 54 Tahun 2010 Tentang Pengadaan Barang/Jasa Pemerintah, Visimedia,Jakarta. Indonesia, 2012, Perubahan Kedua atas Peraturan Presiden Republik Indonesia Nomor 54 Tahun 2010 Tentang Pengadaan Barang/Jasa Pemerintah, Peraturan Presiden Republik Indonesia Tahun 2012, Jakarta.

Kusrini, 2007, Konsep dan Aplikasi Sistem Pendukung Keputusan, Andi Offset, Yogyakarta.

Kusumadewi, S., dkk., 2006, Fuzzy Multi-Attribute Decision Making (Fuzzy MADM), Graha Ilmu, Yogyakarta.

Marimin, 2004, Teknik dan Aplikasi Pengambilan Keputusan Kriteria Majemuk, Grasindo, Jakarta.

Munandar, Tito Aris,2014, Sistem pendukung Keputusan Pemilihan Siswa Kelas Unggulan pada SMA Negeri 1 Sei Rampah Menggunakan Metode TOPSIS,Jurnal Pelita Informatika Budi Darma Volume VI nomor 2, April 2014, ISSN 2301-9425, STMIK Budidarma Medan.

Nugraha, Fajar., Surarso, Bayu., Noramita.,Beta. 2012. Sistem Pendukung Keputusan Pemilihan Pemenang Pengadaan Aset dengan Metode Simple Additive Weighting (SAW), Jurnal Sistem Informasi Bisnis, Universitas Diponegoro.

Power, Daniel J, 2013, Engineering Effective Decision Support Technologis: New Models and Applications, University of Northern lowa, USA.

Sparague, R. H. and Watson H. J. 1993. Decision Support Systems: Putting Theory Into Practice. Englewood Clifts, N.J., Pretice Hall.

Turban, Efraim \& Aronson, Jay E. 2001. Decision Support Systems and Intelligent Systems. 6th edition. Prentice Hall: Upper Saddle River, NJ. 